\title{
Intracranial hemodynamics during intravenous infusion of glyceryl trinitrate
}

\author{
H. K. Iversen · S. Holm · L. Friberg • \\ P. Tfelt-Hansen
}

Received: 25 March 2008/Accepted: 25 March 2008/Published online: 10 April 2008

(c) Springer-Verlag 2008

\begin{abstract}
The mechanisms of glyceryl trinitrate (GTN)induced headache are not fully elucidated. In this study we administered GTN $0.5 \mu \mathrm{g} / \mathrm{kg} / \mathrm{min}$ i.v. for $20 \mathrm{~min}$ in six healthy volunteers. Before, during and $60 \mathrm{~min}$ after the infusion, we investigated regional cerebral blood flow (rCBF), cerebral blood volume (CBV), both estimated with SPECT, and blood flow velocity (BFV) in the middle cerebral artery (MCA), measured with transcranial Doppler. Headache was scored on a numerical verbal rating (010) scale. $\mathrm{rCBF}$ was unchanged, $\mathrm{CBV}$ was slightly increased (13\%) during GTN infusion, whereas BFV decreased both during (20\%) and $60 \mathrm{~min}(15 \%)$ after GTN. Headache was short-lived and maximal during infusion. This discrepancy of time-effect curves for the effect of GTN on headache and dilatation of MCA indicates that MCA is most likely not the primary source of pain in GTNinduced headache. The time-effect curves for the effect of GTN on headache and on dilation of MCA differed markedly. This indicates that MCA is most likely not the primary source of pain in GTN-induced headache.
\end{abstract}

Keywords Glyceryl trinitrate - Headache . Cerebral blood flow . Cerebral blood volume . Transcranial Doppler

H. K. Iversen · P. Tfelt-Hansen ( $₫)$

Department of Neurology, University of Copenhagen,

Glostrup Hospital, 2600 Glostrup, Denmark

e-mail: ptha@glo.regionh.dk

S. Holm $\cdot$ L. Friberg

Department of Clinical Physiology, Bispebjerg Hospital,

Copenhagen, Denmark

\section{Introduction}

The glyceryl trinitrate (GTN) headache model with intravenous administration of the drug is well established [1-4], and has been used to evaluate acute and prophylactic antimigraine drugs [5-9]. GTN causes an immediate mild to moderate headache during infusion in normal subjects [1]. Migraine patients are supersensitive to GTN [3] and GTN causes a delayed headache in $80 \%$ of patients. This headache resembles the usual migraine attacks $[2,10]$ the patients suffer.

The cause of pain in the NO-induced headache is still not fully elucidated. In the present study, we therefore investigated the effect of intravenous GTN in healthy subjects on intracranial hemodynamics: regional cerebral blood flow, cerebral blood volume and blood flow velocity in the middle cerebral artery.

\section{Methods}

Material and measurements

Six healthy subjects, F:M $=2: 4$, with a mean age of 27.5 years (range 22-38 years) participated in the study. Subjects with migraine and subjects with more than one tension-type headache day per month were excluded. The subjects were to be free from any medication for at least a week. They arrived in the laboratory in the morning after abstaining from alcohol and caffeine for $12 \mathrm{~h}$. Following the placing of a catheter in a cubital vein, they rested supine for $30 \mathrm{~min}$ after which baseline measurements were done.

Glyceryl trinitrate in a dose of $0.5 \mu \mathrm{g} / \mathrm{kg} / \mathrm{min}$ was infused intravenously via the catheter in a cubital vein for 20 min by a volume-directed pump (Braun perfusor). 
Headache was scored on a numerical verbal rating scale from 0 to $10(0=$ no headache and $10=$ worst possible pain) [1] every $10 \mathrm{~min}$ before, during, and up to $60 \mathrm{~min}$ after GTN infusion.

The time-averaged mean of the maximal blood velocities $\left(V_{\text {mean }}\right)$ in the right middle cerebral arteries (MCA) was measured with transcranial Doppler (EME TC28) [11]. The fixpoint measurements of $V_{\text {mean }}$ was a point along the MCA, which was free of the bifurcation between the MCA and the anterior cerebral artery, but as close to it as possible [12]. Due to technical reasons and limitation of space in the scanner, the measurements were performed only on the right side.

Regional cerebral blood flow ( $\mathrm{rCBF}$ ) was measured with a highly sensitive, brain-dedicated, fast-rotating, single photon emission computerised tomograph (Tomomatic 232). Each study lasted $4.5 \mathrm{~min}$. A mixture of atmospheric air and ${ }^{133}$ Xenon was re-breathed during the first $1.5 \mathrm{~min}$ through a closed system from a 4-litre reservoir (740 Mbq/ 1). During the last $3 \mathrm{~min}$ the ${ }^{133}$ Xenon mixture was expired against atmospheric air. rCBF was recorded simultaneously in two slices positioned 50 and $90 \mathrm{~mm}$ above and parallel to the orbito-meatal plane. Each slice was 16-mm thick and the distance between the centres of slices was $40 \mathrm{~mm}$. The full width half maximum resolution of the instrument is about $16 \mathrm{~mm}$ in the horizontal plane. $\mathrm{rCBF}$ was calculated according to Celsis et al. [13].

A fixed matrix of regions of interest was superimposed on the $\mathrm{rCBF}$ picture. The shape and size were fitted to the outlines of the brain excluding extracranial flow and regional mean values were calculated within the predefined regions of interest. The matrix was divided into regions of interest representing the hemispheric $\mathrm{rCBF}$ regions and the vascular territories of supply by the anterior-, middle- and posterior cerebral arteries. The maximum whole body radiation was approximately $0.6 \mathrm{mSV}$ per rCBF measurement [14]. rCBF and CBV were measured simultaneously with a highly sensitive, brain-dedicated, fast-rotating single photon emission computerized tomograph, SPECT, equipment (Tomomatic 232) with dual energy window facilities enabling separation of peak energies from Tc$99 \mathrm{~m}$ and Xe-133. rCBF was measured after Xe-133 inhalation and with $41 / 2$ min data sampling. CBV was recorded after intravenous injection of Tc-99 $\mathrm{m}$ labeled erythrocytes [14] and data were corrected for physical and biological decay. Mean $\mathrm{rCBF}$ and $\mathrm{CBV}$ values from the MCA perfusion territory were calculated from a transverse section of the brain obtained $50 \mathrm{~mm}$ above the orbitomeatal plane. During the rCBF measurements end-expiratory $\mathrm{pCO}_{2}$ was monitored using a capnograph. Data were corrected for $\mathrm{pCO}_{2}$. Heart rate and blood pressures were measured every $2 \mathrm{~min}$, except during the rCBF measurements, with an automatic inflatable arm cuff (Tonoprint ${ }^{\circledR}$ ) during the GTN infusion and thereafter every $5 \mathrm{~min}$. Blood samples for determination of counts in the blood were collected at $0,15,30,60,120,150$ and $180 \mathrm{~min}$.

$V_{\text {mean }}, \mathrm{rCBF}$ and $\mathrm{CBV}$ were measured before and after $20 \mathrm{~min}$ of GTN infusion and $60 \mathrm{~min}$ after the infusion.

Statistical evaluation

Responses were calculated in percent of baseline and expressed as mean and standard error of the mean $( \pm$ SEM). Statistical analysis was done with paired $t$ test. $P<0.05$ was considered statistically significant.

\section{Results}

During GTN infusion five of six subjects experienced headache. The median maximum headache score was 3 (range $0-5$ ). The median headache was 0 (range $0-1$ ) $60 \mathrm{~min}$ after termination of the infusion. The cerebral hemodynamic response was, however, the same in all subjects. The cerebral blood volume was slightly increased $13 \pm 2 \%$ (mean SEM) during GTN infusion $(P<0.05)$ and returned to baseline, $-0.3 \pm 3 \%, 60 \mathrm{~min}$ after the end of infusion (Fig. 1). The regional cerebral blood flow (rCBF) in the perfusion territory of the middle cerebral artery (MCA) was used, and $\mathrm{rCBF}$ values from the second and third measurements were corrected $2 \%$ for each $\mathrm{mmHg}$ the end-tidal $\mathrm{pCO}_{2}$ deviated from the control value. There were no significant changes in $\mathrm{rCBF}$ during and after GTN

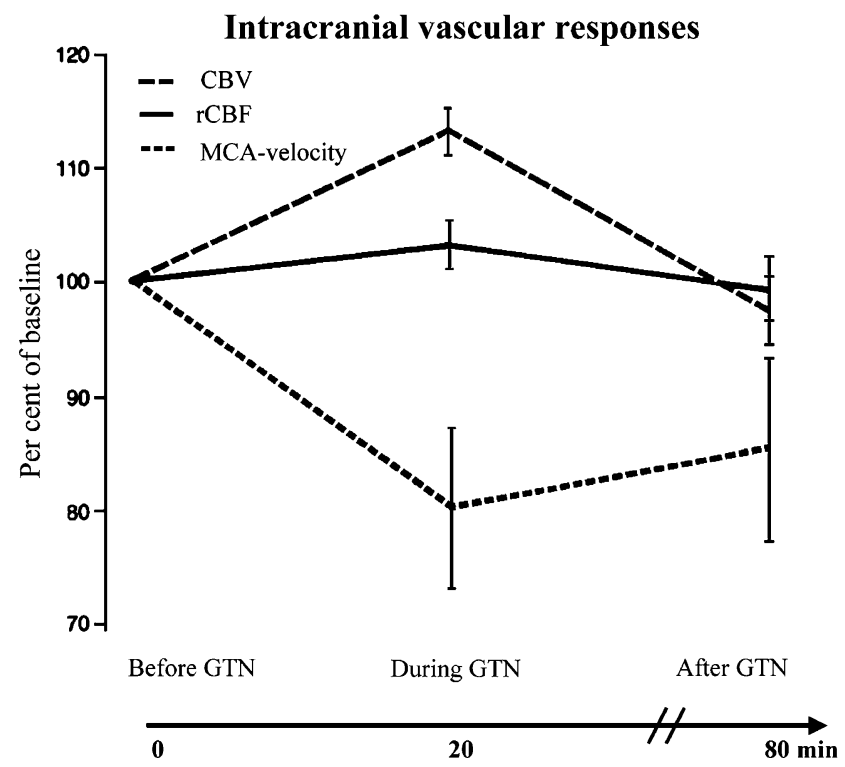

Fig. 1 The effect of glyceryl trinitrate $(0.5 \mu \mathrm{g} / \mathrm{kg} / \mathrm{min})$ i.v. for $20 \mathrm{~min}$ in six healthy volunteers on cerebral blood volume, regional cerebral blood flow and blood flow velocity in the middle cerebral artery 
in fusion (Fig. 1). The mean maximal velocity (baseline $=68 \pm 3 \mathrm{~cm} / \mathrm{s}$ ) in the MCA decreased by $20 \%$ $(P<0.05)$ during infusion (from $68 \pm 3$ to $55 \pm 5 \mathrm{~cm} / \mathrm{s}$ ) and was still decreased by $15 \%(56 \pm 5 \mathrm{~cm} / \mathrm{s}, P<0.05)$ 60 min after infusion (Fig. 1).

Mean systolic BPs were 116, 119 and $120 \mathrm{mmHg}$ $(P=0.42)$. Mean diastolic BPs were 72,84 , and $84 \mathrm{mmHg}(P=0.013)$. Mean heart rate, 69,80 and $66 \mathrm{bpm}$, was unchanged $(P=0.10)$.

\section{Discussion}

Glyceryl trinitrate, an exogenous nitric oxide-donor, is known to cause headache as a side effect when used in cardiovascular diseases [15]. A headache model with intravenous GTN has been developed and evaluated [1-3, $5-10]$. The bioavailability after sublingual GTN $(0.4 \mathrm{mg})$ was $36 \pm 25 \%$ (mean $\pm \mathrm{SD}$ ), range from 3 to $113 \%$ [16]. The time to peak concentration also varied considerably [16]. In our work with the experimental headache model we have therefore chosen to use intravenous administration of GTN, in order to decrease variability of doses given.

In healthy subjects the headache is dose-dependent with a ceiling effect at $0.5 \mu \mathrm{g} / \mathrm{kg} / \mathrm{min}$ [1]. Migraine patients are more sensitive to GTN than tension-type headache patients and controls [17]. The cause of headache in the GTN model is not fully elucidated and it has been suggested that GTN-induced headache is caused both by vascular and by neuronal effects of NO [18, 19].

In the present study five of six subjects experienced headache during the GTN infusion. However, GTN induced equal hemodynamic responses in all subjects. Median maximal headache score was 3 , and the headache decreased when the infusion stopped. That the bother of lying in the scanner amplified the induced headache, cannnot be ruled out. The headache did not fulfil the criteria for migraine, and no delayed headache was observed, as can be observed when GTN is administered to migraine patients [2].

Changes in regional cerebral blood flow (rCBF) are unlikely to cause headache. Thus during attacks of migraine with aura there is oligemia when the headache begins and there is a late hyperemia which persists after the headache [20]. In the present study, rCBF was unchanged during headache induced by GTN (Fig. 1). Similar results, that is unchanged CBF after GTN, were found in one SPECT study [21] and one PET study [22]. In one PET study [23] a $23 \%$ increase in CBF was found after GTN. This PET examination [23] showed, however, a decrease in occipital $\mathrm{rCBF}$ and it is unclear how a general vasodilatator like GTN should cause regional changes in CBF.

This is the first time cerebral blood volume (CBV) after GTN has been investigated. GTN is a potent dilator of peripheral veins [24]. CBV was slightly but statistically significantly increased (13\%). Clinically, it is observed in migraine that headache is usually aggravated by coughing, straining, or undergoing the Valsalva test, which could infer a venous component to the migraine attack $[25,26]$. We did not test for this during the GTN-headache. Applying pressure on the internal jugular veins (Queckenstedt's manoeuvre) during migraine attacks did cause an increase in migraine pain in two studies [27,28] whereas this was not the case in one study [29]. This indicates that there could be a venous component to migraine pain.

Although the Doppler technique does not allow direct measurements of the diameter of the middle cerebral artery (MCA), the relative change in diameter can be estimated from the relation: regional cerebral blood flow $(\mathrm{rCBF})=$ mean velocity $\times$ cross sectional area of the artery $[21,30]$. When rCBF is unchanged (Fig. 1) a decrease in $V_{\text {mean }}$, as in the present study (Fig. 1), will indicate a dilatation of MCA. The decrease in mean blood flow velocity in MCA (Fig. 1) was still present 60 min after GTN infusion indicating dilatation. In contrast, the headache had disappeared at this time point making it unlikely that dilation per se of MCA is the cause of NO-induced headache. This is supported by findings in another study on GTN, where MCA velocities remained decreased $(14 \%, P<0.001)$ at the time of headache resolution [31]. In addition, dilation of the MCA outlasted the headache response after intravenous dipyridamole [32] and sildenafil-induced migraine in migraine patients, but did not affect MCA velocity [33].

A limitation of this study is the lack of a placebo-control but it was not considered feasible to expose the healthy subjects to the double dose of radiation from a total of six SPECT examinations.

In conclusion, regional cerebral blood flow was unchanged after GTN whereas the middle cerebral artery was dilated after GTN. However, because of the discrepancy of the time-effect curve for dilation of MCA and the effect on headache the dilation of the MCA is unlikely to cause NO-induced headache. Alternative causes for headache such as an effect of NO on extracerebral arteries or an effect of $\mathrm{NO}$ on perivascular nerves should be investigated.

Conflict of interest None.

\section{References}

1. Iversen HK, Olesen J, Tfelt-Hansen P (1989) Intravenous nitroglycerin as an experimental model of vascular headache. Basic characteristics. Pain 38:17-24

2. Thomsen LL, Kruuse C, Iversen HK, Olesen J (1994) A nitric oxide donor (nitroglycerin) induce genuine migraine attacks. Eur J Neurol 1:73-80 
3. Olesen J, Iversen HK, Thomsen LL (1993) Nitric oxide supersensitivity. A possible molecular mechanism of migraine pain. Neuroreport 4:1027-1030

4. Olesen J, Thomsen LL, Iversen HK (1994) Nitric oxide is a key molecule in migraine and other vascular headaches. Trends Pharmacol Sci 15:149-153

5. Iversen HK, Olesen J (1996) Headache induced by a nitric oxide donor (nitroglycerin) responds to sumatriptan. A human model for development of migraine drugs. Cephalalgia 16:412-418

6. Schmetterer L, Wolzt M, Krejcy K, Graselli U, Findl O, Eichler H-G, Singer EA (1996) Cerebral and ocular hemodynamic effects of sumatriptan in the nitroglycerin headache model. Clin Pharmacol Ther 60:199-205

7. Tvedskov JF, Thomsen LL, Iversen H, Gibson A, Wiliams P, Olesen J (2004) The prophylactic effect of valproate on glyceryltrinitrate induced migraine. Cephalalgia 24:576-585

8. Tvedskov JF, Thomsen LL, Iversen HK, Williams P, Gibson A, Jenkins K, Peck R, Olesen J (2004) The effect of propranolol on glyceryltrinitate-induced headache and arterial response. Cephalalgia 24:1076-1087

9. Tvedskov JF, Iversen HK, Olesen J (2004) A double-blind study of SB-220453 (Tonerbasat) in the glyceryl trinitrate (GTN) model of migraine. Cephalalgia 24:875-882

10. Afridi SK, Matharu MS, Lee L, Kaube H, Friston KJ, Frackowiak RS, Goadsby PJ (2005) A PET study exploring the laterality of brainstem activation in migraine using glyceryl trinitrate. Brain 128:932-939

11. Aaslid R, Markwalder TM, Nomes H (1982) Noninvasive transcranial Doppler ultrasound recording of flow velocity in basal cerebral arteries. J Neurosurg 57:769-774

12. Thomsen LL, Iversen HK (1993) Experimental and biological variation of three-dimensional transcranial Doppler measurements. J Appl Physiol 75:2805-2810

13. Celsis P, Goldman T, Henriksen L, Lassen NA (1981) A method for calculating regional cerebral blood flow from emission computed tomography of inert gas concentrations. J Comput Assist Tomogr 5:641-645

14. Holm S, Friberg L, Iversen HK, Lassen NA (1990) Dual energy SPECT-methods and applications. In: Schmidt HAE, Chambron J (eds) Nuclear Medicines: Quantitative analysis in imaging and function. Schattauer, Stuttgart, pp 11-13

15. Fletcher A, McLoone P, Bulpitt C (1988) Quality of life on angina therapy: A randomized controlled trial of transdermal glyceryl trinitrate against placebo. Lancet II:4-8

16. Noonan PK, Benet LZ (1985) Incomplete and delayed bioavailability of sublingual nitroglycerin. Am J Cardiol 55:184-187

17. Thomsen LL, Iversen HK, Brinck TA, Olesen J (1993) Arterial supersensitivity to nitric oxide (nitroglycerin) in migraine sufferers. Cephalalgia 13:395-399

18. Iversen HK, Reuter U (2006) Nitric oxide involvement in migraine. In: Olesen J, Goadsby PJ, Ramadan NM, Tfelt-Hansen
P, Welch KMA (eds) The headaches. 3rd ed. Lippincott, Philadelphia, pp 281-287

19. Parson AA (2006) Nitric oxide. In: Olesen J, Goadsby PJ, Ramadan NM, Tfelt-Hansen P, Welch KMA (eds) The headaches. 3rd ed. Lippincott, Philadelphia, pp 151-158

20. Olesen J, Friberg L, Olsen TS, Iversen HK, Lassen NA, Andersen AR, Karle A (1990) Timing and topography of cerebral blood flow, aura, and headache during migraine attacks. Ann Neurol 28:791-798

21. Dahl A, Russell D, Nyberg-Hansen R, Rootwell K (1989) Effect of nitroglycerin on cerebral circulation measured by transcranial Doppler and SPECT. Stroke 20:1733-1736

22. White RP, Deane C, Hindley C, Bloomfield PM, Cunningham VJ, Vallance $P$ et al (2000) The effect of the nitric oxide donor glyceryl trinitrate on global and regional cerebral blood flow in man. J Neurol Sci 178:23-28

23. Bednarczyk EM, Wack DS, Kassab MY, Burch K, Trinidad K, Haka M, Gona J (2002) Brain blood flow in the nitroglycerin (GTN) model of migraine: measurement using positron emission tomography and transcranial Doppler. Cephalalgia 22:749-757

24. Toftgard KE, Ahlner J (1994) Mechanism of action of nitrates. Cardiovasc Drugs Ther 8:701-707

25. Heyck H (1956) Neue Beiträge zur Klinik und Pathogenese der Migräine. Thieme Verlag, Stuttgart

26. Friedman AP (1972) Current concepts in the diagnosis and treatment of chronic recurring headache. Symposium on Clinical Neurology. Med Clin North Am 1257-1271

27. Chou CH, Chao AC, Lu SP, Hu HH, Wang SJ (2004) Cephalic venous congestion aggravates only migraine-like type headaches. Cephalalgia 24:973-979

28. Doepp F, Schreiber SJ, Dreier JP, Einhäupl KM, Valduza JM (2003) Migraine aggravation by cephalic venous congestion. Headache 43:96-98

29. Daugaard D, Olesen J (1998) No relation between cephalic venous dilatation and pain in migraine. $\mathrm{J}$ Neurol Neurosurg Psychiatr 65:260-262

30. Friberg L, Olesen J, Iversen HK, Sperling B (1991) Migraine pain associated with middle cerebral artery dilatation: reversal by sumatriptan. Lancet 338:13-17

31. Tegeler CH, Davidai G, Gengo FM, Kappertz VA, Troost BT, Gabriel H, Davis RL (1996) Middle cerebral artery velocity correlates with nitroglycerin-induced headache onset. J Neuroimaging 6:81-86

32. Kruuse C, Jacobsen TB, Lassen LH, Thomsen LL, Hasselbach SG, Dige-Petersen H, Olesen J (2000) Dipyridamole dilates large cerebral arteries concomitant to headache induction in healthy subjects. J Cereb Blood Flow Metab 20:1372-1379

33. Kruuse C, Thomsen LL, Birk S, Olesen J (2003) Migraine can be induced by sildenafil without changes in middle cerebral artery. Brain 126:241-247 